\title{
Thermal Management Optimization for a Wireless Charging System of Electric Vehicle with Phase Change Materials
}

\author{
Zaiguo $\mathrm{Fu}^{1, *}$, Lingtong $\mathrm{Li}^{1}$, Xiaotian Liang ${ }^{1}$, Qunzhi $\mathrm{Zhu}^{1}$ and Zhiyuan Cheng ${ }^{2}$ \\ ${ }^{1}$ College of Energy and Mechanical Engineering, Shanghai University of Electric Power, Shanghai 200090, China \\ ${ }^{2}$ College of Electric Power Engineering, Shanghai University of Electric Power, Shanghai 200090, China
}

\begin{abstract}
The high-power wireless charging system for the electric vehicle (EV) generates irreversible magnetic loss and quantities of heat during the charging process. Using thermal management with phase change material (PCM) can reduce the temperature rising rate and ensure the operation safety. A thermal management optimization for a $6.6 \mathrm{~kW}$ wireless EV charging system with PCMs was studied. The mathematical model of the heat transfer process in the charging system with thermal management was developed. It was solved by a MATLAB procedure and verified by an experimental measurement. A concept of effective time was proposed as the optimization index to evaluate the performance of the thermal management system. The results indicated that the thermal conductivity of the PCM needed to be improved for a better thermal performance. The modified PCM as paraffin with expanded graphite (EG) was adopted and the optimum thickness and thermal properties were obtained. The effective time by using the optimal PCM layer was 3 and 1.2 times that by using the original PCM layer for the charging system with 5\% and $10 \%$ energy loss, respectively. The optimal layer can keep the temperature of the charging system below $60{ }^{\circ} \mathrm{C}$ in long-term operation.
\end{abstract}

\section{Introduction}

Electric vehicle (EV) plays an important role in solving the increasingly prominent global environmental and energy problems. For the present EV charging system, the cost of the on-board and charging equipment is high and the charging operation is complicate and inflexible [1]. Thus, the wireless charging system is proposed to make the EV charging more convenient. It could be space-saving and easy for operation and maintainance. But the transmitter and receiver of the charging system as shown in Figure 1 will produce irreversible magnetic loss and quantities of heat during the EV charging process. The thermal management of the wireless EV charging system is necessary for ensuring the operation safety and prolonging the service life of the charging system [2].

Many researchers have studied the thermal management of vehicle-mounted battery with phase change material (PCM) from different perspectives, such as the arrangement of PCM [3-5]. The studies have proved that PCM has a positive effect in thermal management [6]. For the wireless EV charging system, the operation efficiency is within $90 \%-95 \%$, indicating that $5 \%-10 \%$ energy is dissipated in the form of heat [7]. However, the study on the thermal management for the high-power wireless charging system of EV with PCM is insufficient. Thus, in this paper, the thermal management optimization with PCM was studied especially for a $6.6 \mathrm{~kW}$ wireless EV charging system.
The verification experiment was conducted and the paraffin with expanded graphite (EG) as the modified PCM was adopted in the numerical study. The thickness and thermal properties of the modified PCM layer were optimized according to the numerical results on the temperature variation of the wireless EV charging system.

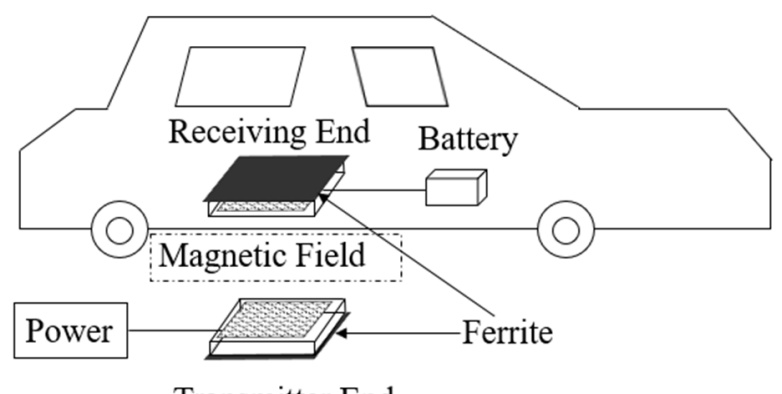

Transmitter End

Fig. 1. The schematic diagram of the wireless EV charging system.

\section{Modelling}

The schematic diagram of the designed thermal management system using air cooling with PCM or without PCM for the wireless EV charging system is shown as Figure 2. The heating layer denotes the coil and the ferrite of the charging system. The PCM layer is integrated with the air cooling method. The following

\footnotetext{
*Corresponding author: fuzaiguo@shiep.edu.cn
} 
assumptions have been made to develop the numerical model of the heat transfer process in this charging system: (1) the horizontal temperature in each layer is uniform except for the air flow; (2) no air thermal resistance exists between the neighboring layers; (3) the heating power of charging system keeps constant during operation.

Based on these assumptions, the practical heat transfer processes are modelled by using energy balance method. The air convection on the cover plate and the phase change process of PCM layer are taken into consideration.

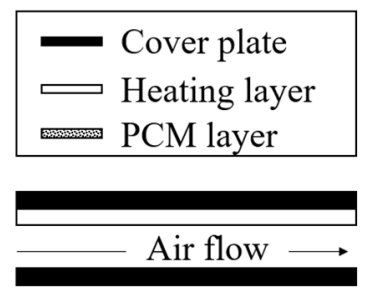

(a)

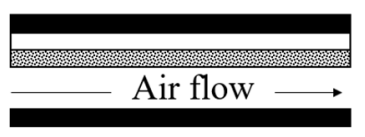

(b)
Fig. 2. The sectional view of the wireless charging system with thermal management (a) without PCM (b) with PCM.

\subsection{Equations}

The energy balance equations for each layer are explained as follows.

\subsubsection{Cover plate}

The heat absorbed by the cover plate is dissipated into surroundings in the form of convection and conduction. The energy balance of the cover plate in a short time (i denotes the time layer) can be written as follows.

For the upper cover plate:

$\rho_{c} V_{c} C_{c} \frac{T_{c}^{i+1}-T_{c}^{i}}{\Delta \tau}=u_{c-h} A\left(T_{c}^{i}-T_{h}^{i}\right)-h_{a t m-c} A\left(T_{a t m}^{i}-T_{c}^{i}\right)$

For the lower cover plate:

$\rho_{c} V_{c} C_{c} \frac{T_{c}^{i+1}-T_{c}^{i}}{\Delta \tau}=h_{a-c} A\left(T_{a}^{i}-T_{c}^{i}\right)-h_{c-a t m} A\left(T_{c}^{i}-T_{a t m}^{i}\right)$

It is noted that $h_{c-a t m}$ or $h_{a t m-c}$ is the overall heat transfer coefficient between the cover plate and the ambient atmosphere. $\rho$ is density and $C$ is specific heat capacity. $A$ is the area of plate.

\subsubsection{Heating layer}

The heat generated by the heating layer is absorbed by the upper cover plate and air flow as shown in Figure 2(a), or the upper cover plate and the lower PCM layer as shown in Figure 2(b). The energy balance of the heating layer in a short time can be written as follows:

$$
\rho_{h} V_{h} C_{h} \frac{T_{h}^{i+1}-T_{h}{ }^{i}}{\Delta \tau}=P-U_{c-h} A\left(T_{c}^{i}-T_{h}{ }^{i}\right)-h_{h-a} A\left(T_{h}^{i}-T_{a}^{i}\right)
$$

$$
\rho_{h} V_{h} C_{h} \frac{{ }_{T_{h}}{ }^{i+1}-T_{h}{ }^{i}}{\Delta \tau}=P-U_{c-h} A\left(T_{c}^{i}-T_{h}{ }^{i}\right)-U_{h-P C M} A\left(T_{h}{ }^{i}-\right.
$$

Where, $U$ is also the overall heat transfer coefficient between the two adjacent layers.

\subsubsection{Air flow}

The energy balance equations of the air flow can be written as follows:

$$
\begin{aligned}
& h_{P C M-a}\left(T_{P C M}-T_{a}\right) W \cdot d x= c_{a} \cdot \dot{m}_{a} \cdot d T_{a}+h_{a-c}\left(T_{a}-\right. \\
&\left.T_{c}\right) W \cdot d x
\end{aligned}
$$

Where, $W$ is the width of the air channel and $\dot{m}_{a}$ is the mass velocity of air flow. $d x$ is a small length along the flow direction.

The mean temperature of air flow is deduced as [8]:

$$
\overline{T_{a}}=T_{a, 0} \cdot R_{1}+\frac{h_{P C M-a} \cdot T_{P C M}+h_{a-c} \cdot T_{C}}{h_{P C M-a}+h_{a-c}}\left(1-R_{1}\right)
$$

Where, $T_{a, 0}$ is the inlet temperature of air flow, $R_{1}=$ $\frac{1-Q_{1}}{P_{1} \cdot L}, P_{1}=\frac{\left(h_{P C M-a}+h_{a-c}\right) W}{C_{a} \cdot \dot{m}_{a}}$, and $Q_{1}=e^{-P_{1} x}$.

\subsubsection{PCM layer}

The heat exchange between the PCM layer and the contiguous layers is mainly in the forms of conduction and convection. It is described as:

$$
Q^{i+1}=Q^{i}+U_{h-P C M} A\left(T_{h}{ }^{i}-T_{P C M}^{i}\right)-h_{P C M-a} A\left(T_{P C M}{ }^{i}-T_{a}^{i}\right)
$$

Where, if $Q_{\text {sol }}<Q<Q_{\text {liq }}, T_{P C M}=T_{m p}, \lambda_{P C M}=$ $\lambda_{\text {sol }} \frac{Q-Q_{\text {sol }}}{Q_{\text {liq }}-Q_{\text {sol }}}+\lambda_{\text {liq }} \frac{Q_{\text {liq }}-Q}{Q_{\text {liq }}-Q_{\text {sol }}} \cdot \lambda$ is the thermal conductivity.

\subsection{Heat transfer coefficients}

For the abovementioned neighbouring layers 1 and 2, the overall heat transfer coefficient is given by:

$$
U_{1-2}=\left(\frac{\delta_{1}}{\lambda_{1}}+\frac{\delta_{2}}{\lambda_{2}}\right)^{-1}
$$

For the air flow and its contiguous layer, the overall heat transfer coefficient is given by:

$$
h_{1-a}=\left(\frac{\delta_{1}}{\lambda_{1}}+\frac{1}{h_{a}}\right)^{-1}
$$

The Nusselt number of air flow can be estimated by an empirical formula [9]:

$\mathrm{Nu}=0.0214\left(\operatorname{Re}^{0.8}-100\right) \operatorname{Pr}^{0.4}\left(\frac{T_{a}}{T}\right)^{0.4}\left[1+\left(\frac{D}{L}\right)^{\frac{2}{3}}\right]$

Where, $D$ is the equivalent diameter and $L$ is the length of air channel.

The convective heat transfer coefficient between air flow and its contiguous layer is given by: 


$$
h_{a}=\mathrm{Nu} \cdot \frac{\lambda_{a}}{D}
$$

With the help of Equations (7), (9) and (10), the overall heat transfer coefficients in the model can be calculated. All equations are solved by a self-made MATLAB procedure to evaluate the temperature of the heating layer, the PCM layer and the air flow.

\section{Results and discussion}

\subsection{Experimental validation}

The experiment was carried out to verify the numerical model and solution by the arrangement as shown in Figure 3. The thermocouples and the data acquisition instrument were used to obtain the temperature of the mimic charging system. The area of each layer in the system is $0.2 \times 0.2 \mathrm{~m}^{2}$ and the wind speed is $5.1 \mathrm{~m} / \mathrm{s}$. The thickness of the air channel, PCM layer, heating layer and insulating layer is $0.02 \mathrm{~m}, 0.02 \mathrm{~m}, 0.03 \mathrm{~m}$ and $0.03 \mathrm{~m}$, respectively. In the experiment, the heating power was set at $3250 \mathrm{~W} / \mathrm{m}^{2}$. This heat flux is same as the $6.6 \mathrm{~kW}$ wireless charging system with $10 \%$ energy loss on a surface of $0.45 \times 0.45 \mathrm{~m}^{2}$. The adopted PCM is the \#60 paraffin. Its specific heat capacity is $2.9 \mathrm{~kJ} /\left(\mathrm{kg} \bullet{ }^{\circ} \mathrm{C}\right)$ in solid phase and $2.1 \mathrm{~kJ} /\left(\mathrm{kg} \cdot{ }^{\circ} \mathrm{C}\right)$ in liquid phase. Its density is $860 \mathrm{~kg} / \mathrm{m}^{3}$. The other thermal properties for this paraffin are presented in Table 1 with those of a modified PCM.

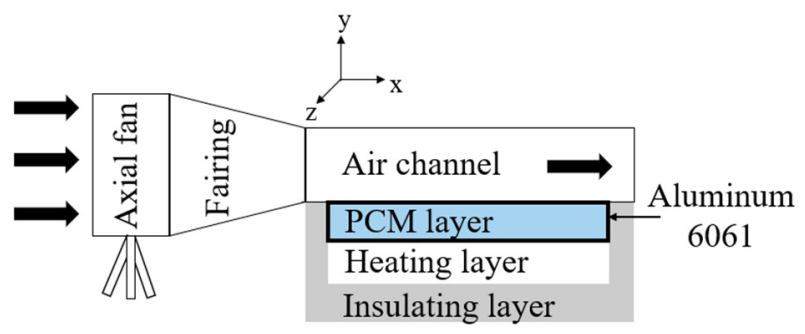

Fig. 3. The schematic diagram of the experimental facility.

The temperature curves during the melting process of the PCM layer in the simulation and experiment are shown in Figure 4. It can be seen that the simulation result has a good agreement with the experimental result except for the melting point. The measured melting point is lagged slightly. This can be explained by the gradual heat transfer and melting process of the paraffin from the bottom to the top position in practice. However, the trends of temperature variation in the simulation and experiment are consistent and the maximum temperature difference is $2.8^{\circ} \mathrm{C}$, indicating the simulation is reliable.

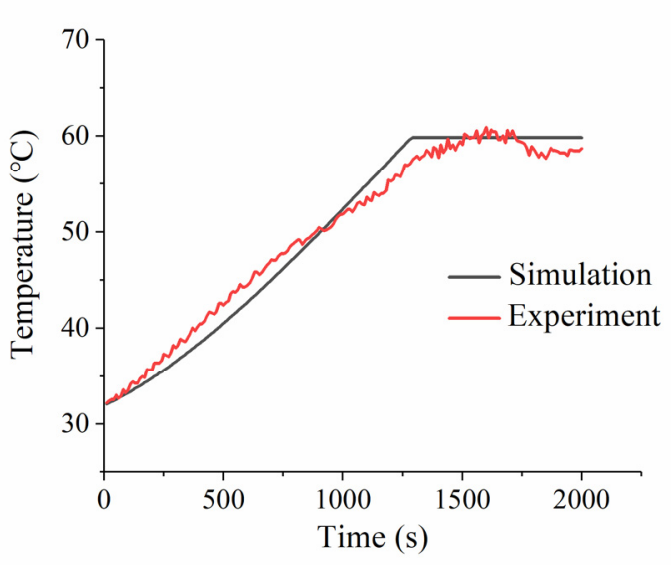

Fig. 4. Temperature curves of the melting process for PCM layer in the simulation and experiment.

\subsection{Effective time}

Figure 5 shows the calculated temperature variations of the heating layer under different conditions of thermal management with no PCM and with PCM. The results reflected that the PCM as pure paraffin needs a modification for this operation condition because of its low thermal conductivity. So the PCM with expanded graphite $(\mathrm{EG} / \mathrm{PCM})$ is put forward to enhance the thermal conductivity. Here, the \#60 paraffin with 9\% (wt.\%) EG is adopted. The main thermal properties of EG/PCM are also listed in Table 1.

As seen from Figure 5, the application of EG/PCM can reduce the rate of temperature rise evidently. Moreover, there is a time range in which the EG/PCM can keep the temperature of heating layer less than that without PCM under other same conditions. This time range is defined as the effective time. It can be applied to describe the influence degree of the thermal management system with EG/PCM. In the optimization design of this modified PCM layer, the effective time affected by the thickness and thermal properties needs to be as long as possible.

Table 1. Thermal properties of the PCM and EG/PCM.

\begin{tabular}{|c|c|c|}
\hline Type & PCM & EG/PCM [10] \\
\hline Component & $\# 60$ paraffin & $\begin{array}{c}9 \% \text { EG and } \# 60 \\
\text { paraffin }\end{array}$ \\
\hline Thermal conductivity & $0.24 \mathrm{~W} /\left(\mathrm{m} \cdot{ }^{\circ} \mathrm{C}\right)$ & $0.94 \mathrm{~W} /\left(\mathrm{m} \bullet{ }^{\circ} \mathrm{C}\right)$ \\
\hline Latent heat & $210 \mathrm{~kJ} / \mathrm{kg}$ & $143 \mathrm{~kJ} / \mathrm{kg}$ \\
\hline Melting point & $60^{\circ} \mathrm{C}$ & $54.5^{\circ} \mathrm{C}$ \\
\hline
\end{tabular}




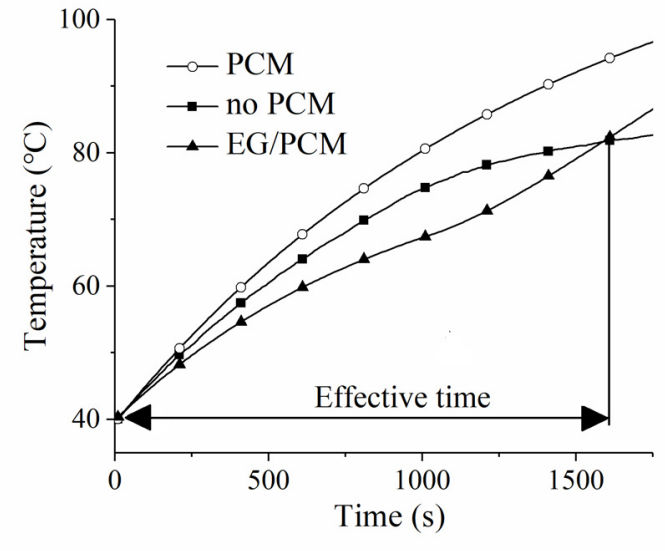

Fig. 5. The schematic of the concept of effective time.

\subsection{Optimal thickness of PCM layer}

Figure 6 shows the effective time under various thickness of the PCM layer for a $6.6 \mathrm{~kW}$ charging system with $5 \%$ and $10 \%$ energy loss, respectively. It is found that there are three characteristic stages with the thickening of the PCM layer for the charging system with $10 \%$ heat loss. The effective time increases with the thickening of PCM layer from $0.001 \mathrm{~m}$ to $0.015 \mathrm{~m}$, and reaches peak value of 2928s. Under this condition, the dissipated heat is all absorbed by the PCM and the advantage of PCM is fully utilized in this process. When the thickness increases from $0.016 \mathrm{~m}$ to $0.022 \mathrm{~m}$, the PCM layer still works even at a low performance. The thick PCM layer partly suppresses the heat conduction. When the thickness exceeds $0.022 \mathrm{~m}$, the effective time is limited and the application of PCM has little effect.

With respect to the effective time for the charging system with 5\% energy loss, it can be seen from Figure 6 that when the thickness of the PCM layer is less than $0.003 \mathrm{~m}$ or more than $0.047 \mathrm{~m}$, the effective time is limited and the application of PCM has little effect. This indicates the too thin or thick PCM layer is not appropriate for the thermal management under the condition. As the PCM layer thickens from $0.004 \mathrm{~m}$ to $0.046 \mathrm{~m}$, the effective time increases firstly and then decreases. A too thin PCM layer has a very small thermal resistance and results in a small temperature rise of the PCM layer. Thus, the PCM cannot be melt and absorb heat. In contrast, a too thick PCM layer has a large thermal resistance and results in a large temperature rise of the heating layer. It is clearly seen that the optimum thickness is also $0.015 \mathrm{~m}$ and its corresponding effective time is 1530 s.

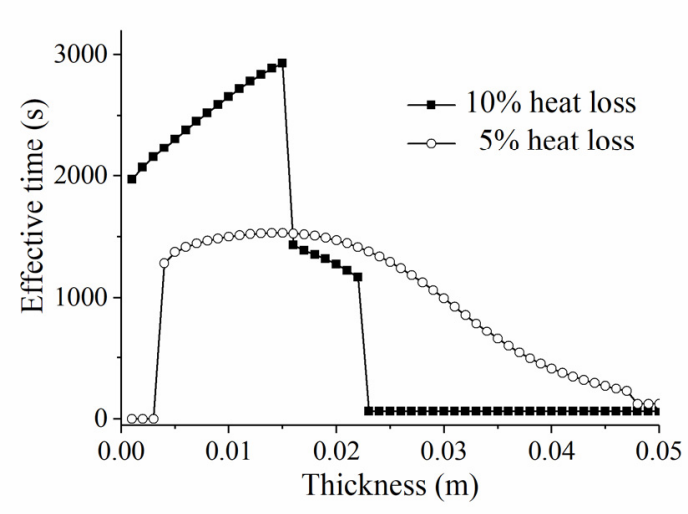

Fig. 6. The effective time for a $6.6 \mathrm{~kW}$ wireless EV charging system with $5 \%$ and $10 \%$ energy loss under various thickness of PCM layer.

\subsection{Optimal thermal properties of PCM layer}

In order to obtain more excellent thermal performance of the thermal management system, the thermal conductivity, melting point and latent heat of the modified PCM are optimized further. Each case is studied with a varying property under the other same properties and conditions optimized in previous section.

\subsubsection{Thermal conductivity}

Figure 7 shows the effective time with the thermal conductivity of $\mathrm{PCM}$ changed from $0.05 \mathrm{~W} /\left(\mathrm{m} \cdot{ }^{\circ} \mathrm{C}\right)$ to 1 $\mathrm{W} /\left(\mathrm{m} \cdot{ }^{\circ} \mathrm{C}\right)$ for the charging system with $10 \%$ and $5 \%$ energy loss. It indicates that the thermal conductivity of PCM should be larger than $0.6 \mathrm{~W} /\left(\mathrm{m} \cdot{ }^{\circ} \mathrm{C}\right)$ and 0.3 $\mathrm{W} /\left(\mathrm{m} \cdot{ }^{\circ} \mathrm{C}\right)$ respectively to take effect for the cases with $5 \%$ and $10 \%$ energy loss. The thermal conductivity should exceed $0.9 \mathrm{~W} /\left(\mathrm{m} \bullet{ }^{\circ} \mathrm{C}\right)$ for a better performance.

\subsubsection{Melting point}

Figure 8 shows the effective time with the melting point changed from $20^{\circ} \mathrm{C}$ to $120^{\circ} \mathrm{C}$ for the charging system with $10 \%$ and $5 \%$ energy loss. It indicates that the melting point of PCM should be less than $37^{\circ} \mathrm{C}$ and $57{ }^{\circ} \mathrm{C}$ respectively to take effect for the two conditions of $5 \%$ and $10 \%$ energy loss. In the proposed range of melting point, increasing melting point can extend the effective time. 


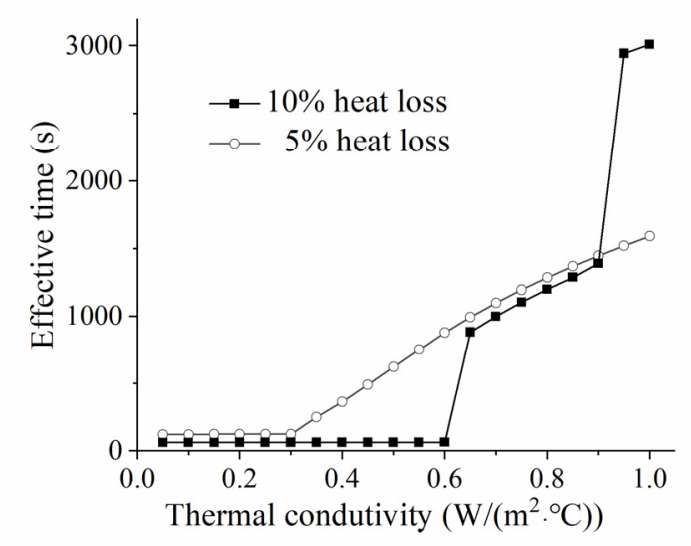

Fig. 7. The effective time for a $6.6 \mathrm{~kW}$ wireless EV charging system with $5 \%$ and $10 \%$ energy loss under various thermal conductivity of PCM.

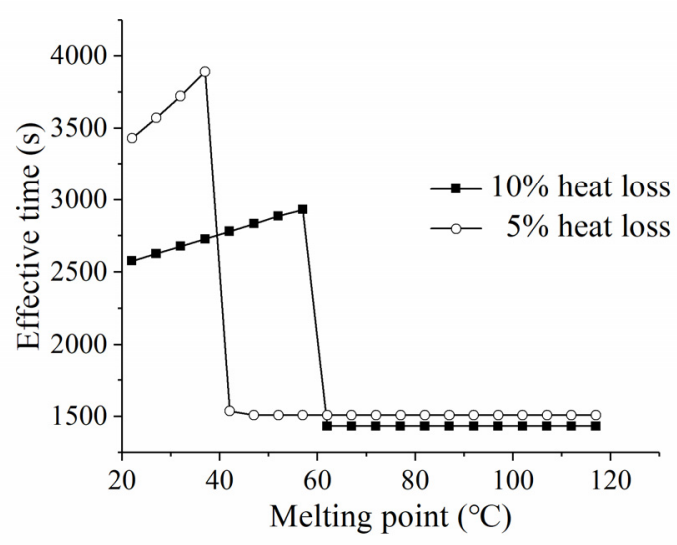

Fig. 8. The effective time for a $6.6 \mathrm{~kW}$ wireless EV charging system with $5 \%$ and $10 \%$ energy loss under various melting point of PCM.

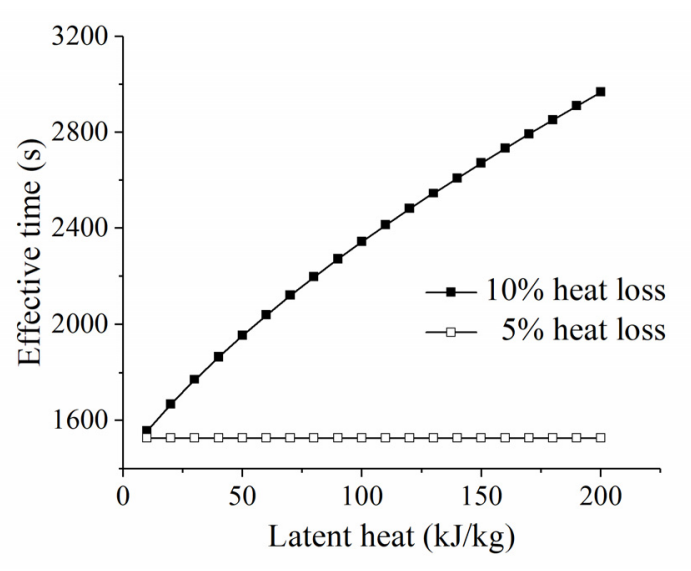

Fig. 9. The effective time for a $6.6 \mathrm{~kW}$ wireless $\mathrm{EV}$ charging system with $5 \%$ and $10 \%$ energy loss under various latent heat of PCM.

\subsubsection{Latent heat}

Figure 9 shows the effective time with the latent heat changed from $10 \mathrm{~kJ} / \mathrm{kg}$ to $200 \mathrm{~kJ} / \mathrm{kg}$. It indicates that the increasing latent heat can prolong the effective time under the condition of $10 \%$ energy loss. However, it is invalid for the $5 \%$ energy loss case due to the difficulty of the PCM to be melt.

\subsection{Thermal performance by optimization}

The temperature variations of the heating layer and the cover plate are shown in Figure 10 to reveal the thermal performance with the optimal parameters. For the case with $10 \%$ energy loss, it is found that the effective time is prolonged to $3400 \mathrm{~s}$, which is 1.2 times that using original EG/PCM. The temperature of heating plate and cover plate keeps below $120{ }^{\circ} \mathrm{C}$ and $60{ }^{\circ} \mathrm{C}$ respectively in $3500 \mathrm{~s}$, which ensure the operation safety and avoid high temperature on surface. For the case with 5\% energy loss, it is found that the effective time is prolonged to $4500 \mathrm{~s}$, which is 3 times that using original EG/PCM. The temperature of heating plate and cover plate keeps below $90{ }^{\circ} \mathrm{C}$ and $60{ }^{\circ} \mathrm{C}$ respectively in 5000s, indicting the thermal management optimization is effective and the operation safety is well guaranteed.

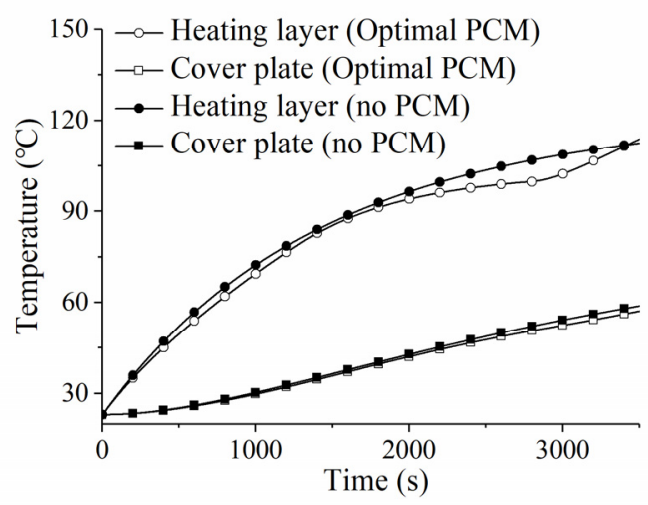

(a)

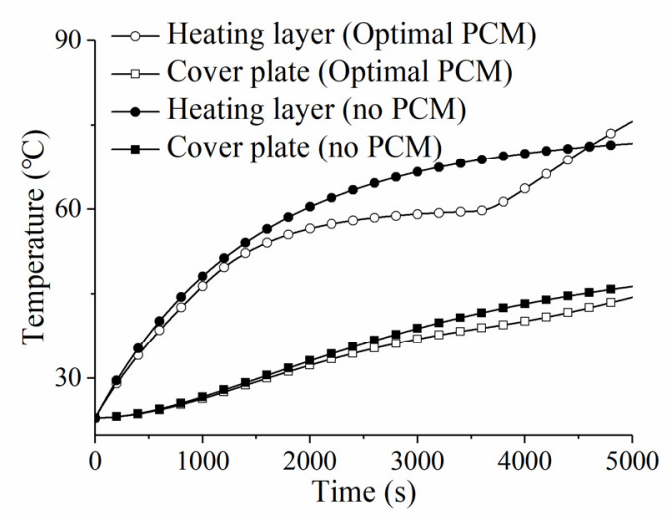

(b)

Fig. 10. The temperature variations of cover plate and heating layer with (a) $10 \%$ energy loss (b) $5 \%$ energy loss by thermal management optimization.

\section{Conclusions}

In this work, the thermal management optimization for a high-power wireless EV charging system has been conducted. The PCM as pure paraffin is modified by adding EG to enhance the thermal conductivity. The 
thickness and thermal properties were optimized for the charging system with $5 \%$ and $10 \%$ energy loss respectively. The following conclusions are addressed:

(1) For the case with 5\% energy loss, the optimum thickness of the EG/PCM layer is $0.015 \mathrm{~m}$ and its effective time is $1530 \mathrm{~s}$. The thermal conductivity of the modified PCM layer need to exceed $0.3 \mathrm{~W} /\left(\mathrm{m} \cdot{ }^{\circ} \mathrm{C}\right)$, and the melting point should below $37^{\circ} \mathrm{C}$.

(2) For the case with $10 \%$ energy loss, the optimum thickness of the EG/PCM layer is $0.015 \mathrm{~m}$ and its effective time is 2928s. The thermal conductivity of the modified PCM layer need to exceed $0.6 \mathrm{~W} /\left(\mathrm{m} \bullet{ }^{\circ} \mathrm{C}\right)$, and the melting point should below $57^{\circ} \mathrm{C}$. The increased latent heat of the PCM prolongs the effective time.

(3) The PCM layer with optimal thickness and thermal properties has a positive effect on the thermal management for the charging system. The effective time is 1.2 and 3 times than that using unmodified PCM for the case with $10 \%$ and $5 \%$ energy loss, respectively. The temperature of the cover plate is below $60^{\circ} \mathrm{C}$ in operation over 1 hour.

\section{Acknowledgement}

The supports by the National Science Foundation of China (NO.51606114) and Science and Technology Commission of Shanghai Municipality (STCSM NO.18020501000) to this study are acknowledged and highly appreciated.

\section{References}

1. S.W. Choi, Y.J. Kim, J.Y. Lee, EPE Journal, 1, 1124(2019)

2. G.V. Carlos Andres, L.I. Francisco, F.R. Luis M, S.S. Higinio, J. Franxisco, Energy, 137, $42-57$ (2017)

3. M. Thota, K. Jaya, K. Kumar, Indian J. Sci. Technol. 9, (2016)

4. M.D. Li, P. Liang, Appl. Mech. Mater. 433-435, 2107-2112 (2013)

5. G.H. Kim, J. Gonder, J. Lustbader, A. Pesaran, World Electr. Veh. J. 2, 134-147 (2008).

6. Y.Y. Mao, J. Wang, J.M. Li, Appl. Therm. Eng. 137, 356-367 (2018)

7. B. Andreas, A. Matteo, V. Sanna, O. Jesus A, C. Jose A, H. Mario, IEEE Trans. Power Electron. 30, (2015)

8. D. Su, Y. Jia, G. Alva, L. Liu, G. Fang, Energy Convers. Manage. 131, 79-89 (2017)

9. V. Gnielinski, Int. Chem, Eng. 16, 359-368 (1976)

10. T.C. Chang, S. Lee, Y.K. Fuh, Y.C. Peng, Z.Y. Lin, Appl. Therm. Eng. 112, 1129-1136 (2017) 